\title{
Antidiabetic Activity of Hydromethanolic Extract of Crude Dorstenia barnimiana Root: Validation of In Vitro and In Vivo Antidiabetic and Antidyslipidemic Activity
}

\author{
Woretaw Sisay (D), Yared Andargie (D), Mulugeta Molla \\ Department of Pharmacy, College of Health Sciences, Debre Tabor University, Debre Tabor, Ethiopia \\ Correspondence: Woretaw Sisay, Email sisayworetaw@gmail.com; woresis@dtu.edu.et
}

\begin{abstract}
Background: Despite modern therapeutic armamentaria, DM remains a 21st-century public health menace. Novel phytomedicines are a rapidly expanding focus of research. The juice of Dorstenia barnimiana roots has long been used for the treatment of diabetes mellitus in traditional Ethiopian medicine, but its efficacy has not been supported by in vitro or in vivo scientific study. To investigate this, the present work was performed.

Methods: In this experimental study, simple random sampling was applied. Healthy male mice were used in normoglycemic and oral glucose-tolerance test (OGTT) models. Streptozotocin (IP, $150 \mathrm{mg} / \mathrm{kg}$ )-administered diabetic male mice were utilized. Animals were randomly divided into five groups of six each. Group I received $10 \mathrm{~mL} / \mathrm{kg}$ distilled water, groups II-IV received 100 (DB100), 200 (DB200), and 400 (DB400) mg/kg crude extract, respectively, and group V received glibenclamide $5 \mathrm{mg} / \mathrm{kg}$. A sham group (group VI) was added that received $10 \mathrm{~mL} / \mathrm{kg}$ distilled water. All treatments were given orally. FBG, serum-lipid profiles, and body-weight changes were then measured. In vitro $\alpha$-amylase inhibitory activity was also evaluated.

Results: The doses were atoxic up to $2,000 \mathrm{mg} / \mathrm{kg}$. There was $\alpha$-amylase inhibition activity of $67.52 \%$ at $500 \mu \mathrm{g} / \mathrm{mL}$ with an $\mathrm{IC}_{50}$ of $4.595 \mu \mathrm{g} / \mathrm{mL}$. The OGTT revealed an antihyperglycemic effect of the crude extract. This was not attributed to a hypoglycemic side effect. In the diabetic mouse model, it shrank FBG levels remarkably. There were also significant reductions in serum TC, TGs, VLDL-C, and LDL-C. Nevertheless, HDL-C and body-weight levels returned.
\end{abstract}

Conclusion: The present study confirmed the safety and promising in vivo antidiabetic and antidyslipidemic activity of $D$. barnimiana, thus corroborating the traditional claim.

Keywords: antidiabetic, antidyslipidemic, D. barnimiana, streptozotocin, $\alpha$-amylase

\section{Introduction}

Diabetes mellitus (DM) is a chronic metabolic disease attributed to hyperglycemia, hyperlipidemia, and hyperaminoacidemia, along with insulin insufficiency, insulin-receptor resistance, or both. ${ }^{1}$ It affects nearly $10 \%$ of the global population. Despite the introduction of modern hypoglycemic agents, secondary complications remain a major medical issue. Also, most modern drugs have drawbacks, such as gastrointestinal disorders and weight gain. ${ }^{2}$ Multiple pathogenic processes are engaged in the inauguration of DM, such as autoimmune destruction of $\beta$ cells of the pancreas and others precipitating insulin resistance or both. ${ }^{3}$ Among the different types of DM, type 2 is more prevalent worldwide. DM is related to microvascular and macrovascular complications. ${ }^{4}$ Hyperglycemia is an important risk factor in the establishment and prognosis of complications. ${ }^{5}$ It is the third-leading cause of death, next to heart attacks and cancer. ${ }^{6,7}$

Since ancient time, medicinal plants have been part and parcel of human attempts to fight diseases, including DM. ${ }^{8}$ According to a WHO estimation, around $80 \%$ of the population in the developing world relies on traditional phytomedicines for primary health-care needs. ${ }^{9}$ Near to $25 \%$ of contemporary medicines originate from traditional medicinal plants. For 
example, metformin was detected in Galega officinalis. ${ }^{10}$ Based on ethnobotanical studies, there are $>1,200$ medicinal plants involved in DM treatment, due to their efficacy, few side effects, ease of use, and accessibility. ${ }^{11}$

The WHO has suggested the appraisal of cultural medicinal plant treatments consideredexcellent potential for addressing for DM. ${ }^{12}$ The leaves of Croton macrostachys, ${ }^{13}$ Hypoestes forskaolii, ${ }^{14}$ Thymus schimperi, ${ }^{15}$ Rubus erlangeri,${ }^{16}$ Bersama abyssinica,${ }^{17}$ Calpurnia aurea,${ }^{18}$ Ajuga remota,${ }^{9}$ Otostegia integrifolia,${ }^{19}$ roots of Morus alba,${ }^{11}$ Polystachyus delile ${ }^{20}$ and Ficus religiosa, Datura stramonium ${ }^{21}$ and Schinus molle seed extracts, ${ }^{22}$ Hagenia abyssinica flowers, ${ }^{23}$ and Ficus bengalensis, ${ }^{11}$ and Terminalia brownii stem bark ${ }^{24}$ are some of the medicinal plants used in traditional Ethiopian medicine for the treatment of DM. Single-plant preparations and formulated mixtures have been utilized for DM management. For example, dendrobium mixtureand fufang zhenzhu tiaozhi formula are preparations used in traditional Chinese medicine for long-term clinical treatment of DM and its complications. ${ }^{25,26}$

Dorstenia barnimiana is one herb with an indispensable role in the treatment of DM. It is a seasonal African plant used in Ethiopian folk medicine for multiple diseases. In many regions of Ethiopia, the root of the plant is used against common colds, and the leaves are used to remove retained placenta. ${ }^{27}$ Its root powder is used for treatment of hepatitis, rabies, syphilis, unhealthy weight loss, dysentery, fever, hypertension, diarrhea, and DM. ${ }^{28}$ The whole plant has been used for the treatment of schizophrenia via inhalation. ${ }^{29}$ Crushed D. barnimiana leaves have been applied topically for wound healing. ${ }^{30}$ Its root powder has shown antiplasmodial activity in a mouse model. ${ }^{31}$ Other medicinal plants in the same family and genus have confirmed anti-DM effects, eg, D. psilurus and D. picta. ${ }^{32}$ Dorstenia is a potential source of secondary metabolites, such as steroids, benzofuran derivatives, prenylated and geranylated coumarins, flavonoids, styrenes, and triterpenoids. ${ }^{33,34}$ Despite the fact that $D$. barnimiana juice from dry roots mashed and mixed with water has been used for the treatment of DM in traditional Ethiopian medicine, there has been neither in vivo nor in vitro scientific study on its antidiabetic activity to our knowledge. To investigate its use, the current study evaluated $D$. barnimiana's antidiabetic and antidyslipidemic effects in vitro in animals.

\section{Methods}

\section{Drugs and Chemicals}

Drugs, chemicals, and instruments used in the experiment were absolute methanol (ReAgentchem), $0.9 \%$ normal saline (Cadila Pharmaceuticals), distilled water (EPharm), chloroform, ethyl acetate (Nice Laboratory Reagent), examination gloves, 0.5\% trisodium citrate (Loba Chemie), 95\% sulfuric acid (Thermo Fisher Scientific), Dragendorff's reagent (Super-Tek), glacial acetic acid (Loba Chemie), benzene (Nice Laboratory Reagent), ammonia solution (HiMedia), $\mathrm{FeCl}_{3}$ (Super-Tek), 10\% ammonium hydroxide (Rankem), porcine $\alpha$-amylase (Molychem), $0.01 \mathrm{~N}$ sodium hydroxide (Blulux Laboratories), acetic anhydride and Mayer's reagent (May and Baker), 40\% glucose solution (Reyoung Pharmaceuticals), glibenclamide (Glc; Cadila Pharmaceuticals), streptozotocin (Stz; Thermo Fisher Scientific), acarbose (Bayer), and analytical graded syringes were purchased from Addis Ababa pharmaceutical and chemical suppliers.

\section{Apparatus and Supplies}

Instruments, apparatus, and supplies used in the experiment a mini orbital shaker (Stuart Scientific), digital weighing balance, lyophilizer (Wagtech Jouan Nordic DK-3450), deep freezer, Whatman filter paper (number 1, Schleicher and Schuell Microscience), permanent marker, test tubes, volumetric flasks, Erlenmeyer flasks, measuring cylinder, mouse cages, gavages (oral feeding syringes), syringes $(1 \mathrm{~mL}$ and $3 \mathrm{~mL}$ ), desiccators, refrigerator, micro-hematocrit centrifuge, digital thermometer, surgical blades, one-touch basic glucometer and test strip (Hoffman-La Roche), UV-visible spectrophotometer (Agilent Technologies), grinder (KZ-III), rota vapor (Rotary Evaporator RE300), and BS-240 clinical chemistry analyzer (Mindray).

\section{Experimental Animals}

Male Swiss albino mice (body weight 27-35 g, age 8-12 weeks) were used in the present study, except for the acute oral toxicity study, where healthy nonpregnant and nulliparous female mice (body weight 27-35 g, age, 8-12 weeks) were used. The mice were purchased from the Ethiopian Health and Nutrition Research Institute and kept at the animal house of the Pharmacy Department, Debre Tabor University. Animals were housed in ventilated cages at $25^{\circ} \pm 2^{\circ} \mathrm{C}$ and a 12 - 
hour light-dark cycle, with free access to water and standard mouse pellets ad libitum. After indiscriminate grouping and before the commencement of the experiment, animals were acclimatized for 2 weeks. This period allowed them to adapt a strange environment and also promote reproducible experimental outcomes. All experimental protocols were followed as per the guiding principles for research involving animals and as approved by the Research and Ethics Review Committee of the College of Health Sciences, Debre Tabor University, Ethiopia.

\section{Collection and Authentication of Plant Materials}

Roots of D. barnimiana were collected at Fogera, Debub Gondar, Amhara in May 2021. Botanical identification and authentication were done by a taxonomist at the Department of Biology, College of Natural and Computational Sciences, University of Gondar, and a voucher specimen (Wor2/2021) was deposited there for future reference.

\section{Preparation and Extraction of the Plant}

After collection, roots were initially washed using running tap water to remove extraneous materials, air-dried under shade in the Debre Tabor University pharmacology laboratory, then chopped into small pieces and ground into coarse powder. The crude $80 \%$ methanolic crude extract of the root of $D$. barnimiana was prepared by cold maceration. After weighing $1,000 \mathrm{~g}$ coarsely powdered root using a sensitive digital weighing balance, it was soaked into three clean Erlenmeyer conical flasks, each containing 2 L 80\% methanol. Flasks were then placed on a shaker at $120 \mathrm{rpm}$ for 72 hours at room temperature for intermittent agitation. The entire mixture was first filtered through a funnel plunged with muslin cloth twice, then the filtrate was passed through Whatman filter paper (number 1). After filtration, the remaining residue or marc was remacerated twice for 6 days with a fresh solvent of $80 \%$ methanol to maximize the yield. The resulting solution after successive filtration was concentrated using a rotary evaporator set at $40^{\circ} \mathrm{C}$ to remove methanol. Finally, the concentrated aqueous filtrate was placed in the deep freezer overnight, then subjected to lyophilization at $-50^{\circ} \mathrm{C}$ and vacuum pressure to remove water. The percentage yield of the powdered extract was calculated, and it was kept in an airtight container at $-4^{\circ} \mathrm{C}$ until used. ${ }^{35}$

\section{Preliminary Phytochemical Analysis}

Qualitative preliminary phytochemical profiling tests were carried out to determine the presence or absence of major classes of phytochemicals for an $80 \%$ methanol crude extract of the root of D. barnimiana using standard tests. ${ }^{36,37}$

\section{Acute Oral Toxicity Study}

The median lethal dose $\left(\mathrm{LD}_{50}\right)$ of $D$. barnimiana extract was estimated orally in the female mice following the 2008 Organization for Economic Cooperation and Development guideline 425. Accordingly, five female mice aged 6-8 weeks were engaged. All mice were fasted (food but not water) for 4 hours before and 2 hours after administration of the extract. First, a sighting study was performed to determine the starting dose. For this, $2,000 \mathrm{mg} / \mathrm{kg}$ was given per mouse by oral gavage. The first animal received a limited dose of $2,000 \mathrm{mg} / \mathrm{kg}$ and monitored for death for the last 24 hours. Then, four other mice were sequentially treated. The animals were housed separately and observed externally for 4 hours with 30-minute intervals and then for 14 consecutive days, with an interval of 24 hours for general signs and symptoms of toxicity, like food and water intake, death, changes in skin and fur, eyes, and mucous membranes, and respiratory and behavior patterns. ${ }^{38}$

\section{Determination of $\alpha$-Amylase Inhibition Activity}

Commenced using the chromogenic 3,5-dinitrosalicylic acid (DNSA) method in congruent with previous studies. ${ }^{17}$ The hydromethanolic crude extract of $D$. barnimiana root and standard agent (acarbose) were first dissolved in PBS. Sample concentrations of $50-500 \mu \mathrm{g} / \mathrm{mL}$ were prepared accordingly. $\alpha$-Amylase solution $(200 \mu \mathrm{L})$ was mixed with an equal volume of each concentration of the extract and acarbose and incubated for 10 minutes. Afterward, an equal volume of the starch solution ( $1 \%$ in water, w/v) was added to each test tube. The reaction was ended after 3 minutes upon adding $200 \mu \mathrm{L}$ DNSA, then boiled for 10 minutes in a water bath at $85^{\circ} \mathrm{C}$. Thereafter, it was allowed to cool to room temperature and $5 \mathrm{~mL}$ of DW was added. UV-visible spectrophotometry at $540 \mathrm{~nm}$ wavelength was used to measure absorbance capacity. The blank with full enzyme kinetics was created by mixing $200 \mu \mathrm{L}$ enzyme with an equal volume of buffer. A control blank solution, and sample blank (extract or acarbose) without enzyme were created in a similar fashion. The $\alpha-$ 
amylase inhibitory activity is articulated as percentage inhibition and was calculated using the equation given below. ${ }^{23}$ Finally, $\alpha$-amylase inhibition was plotted against the extract and standard concentration:

$$
\text { Inhibition }(\%)=\frac{(A c-A c b)-(A s-A s b)}{A c-A c b} \times 100
$$

where $A c$ refers to absorbance of the control (enzyme and buffer), $A c b$ absorbance of the control blank (buffer without enzyme), $A s$ absorbance of the sample (enzyme and inhibitor), and $A s b$ absorbance of the sample blank (inhibitor without enzyme).

\section{Grouping and Dosing}

Simple random sampling was utilized for the organization of experimental groups and allocation of treatment types. Male mice were involved in all models in this study, due to insensitivity of female mice to Stz and insulin. ${ }^{39,40}$ In normoglycemic and oral glucose-loaded models, overnight-fasted normal mice were arbitrarily placed into five groups. Group I (negative control) received distilled water (DW10, $10 \mathrm{~mL} / \mathrm{kg}$, PO), groups II-IV $100 \mathrm{mg} / \mathrm{kg}$ (DB100), $200 \mathrm{mg} / \mathrm{kg}$ (DB200), and $400 \mathrm{mg} / \mathrm{kg}$ (DB400) hydromethanolic root extract of D. barnimiana PO, respectively, and group V (positive control) $5 \mathrm{mg} / \mathrm{kg}$ glibenclamide (Glc5).

In the Stz-induced diabetic model, overnight fasted-diabetic mice were randomly divided into six groups and treated:

Group I: Diabetic controls DW10

Group II: Diabetic mice DB100

Group III: Diabetic mice DB200

Group IV: Diabetic mice DB400

Group V: Diabetic mice Glc5

Group VI: Normal controls (sham group) DW10

\section{Determination of Parametric Measures}

A blood sample was withdrawn from the tail vein of each fasted mouse aseptically in all animal models. Blood-glucose (BG) levels were measured using the electronic glucometer and test strip. Average values were calculated after triplicate measurements of fasting BG (FBG), body weight, and sample weight.

\section{Induction of Experimental DM}

Stz solubilized in $0.1 \mathrm{M}$ citrate buffer $(\mathrm{pH} 4.5)$ was applied. Stz $(150 \mathrm{mg} / \mathrm{kg}$ ) solution was administered IP to overnightfasted mice. Thirty minutes after Stz administration, normal pellet feeding was allowed. Six hours later, in order to avert deaths associated with hypoglycemic, episodes animals were given access to $5 \%$ glucose solution for a day. Three days later, they were screened for DM, and mice with FBG $>200 \mathrm{mg} / \mathrm{dL}$ were used for further study. ${ }^{41,42}$

\section{Determination of Hypoglycemic Effects in Normoglycemic Mice}

Normal mice were fasted overnight, but had water ad libitum. Then, they were partitioned into the five. After treatment, the BG level (BGL) of each mouse was evaluated before treatment at baseline and then at 1, 2, 4, and 6 hours posttreatment. $^{24}$

\section{Determination of Antihyperglycemic Effects in Oral Glucose-Loaded Mice}

Thirty fasted mice were assigned indiscriminately into five groups and then treatment was administered accordingly. Glucose solution $(40 \% \mathrm{w} / \mathrm{v}, 2 \mathrm{~g} / \mathrm{kg})$ was given to each mouse orally after 30 minutes' therapy. The BGL of each mouse was evaluated prior to oral glucose loading (baseline) and then at 30,60, 90, and 120 minutes after glucose introduction. ${ }^{24}$

\section{Determination of Effects of the Extract on Blood Glucose, Lipid Profile, and Body Weight of Diabetic Mice} Stz-induced diabetic and normal male mice were partitioned arbitrarily into six groups. Treatment was given to mice once daily for 4 consecutive weeks. At $0,7,14,21$, and 28days, FBG and body weight were evaluated. The weight of each mouse had also been measured before induction of DM. Before the end of the experiment, mice were euthanized humanely with pentobarbitone $150 \mathrm{mg} / \mathrm{kg} \mathrm{IP},{ }^{43}$ then blood samples collected via decapitation. The samples were used to 
measure the level of total cholesterol (TC), triglycerides (TGs), and low-density lipoprotein (LDL), very low-density lipoprotein (VLDL), and high-density lipoprotein (HDL) cholesterol (HDL-C) ${ }^{35}$

\section{Statistical Analysis}

$\mathrm{IC}_{50}$ values were calculated from plots of inhibitor concentration versus percentage inhibition of standard curves. Data are given as means \pm SEM and were analyzed using SPSS 24 . Between- and within-group analyses were done using oneway ANOVA followed by post hoc Tukey multiple-comparison tests. $P<0.05$ was considered statistically significant.

\section{Results}

\section{Yield Determination}

From 1,000 g root powder of D. barnimiana, $406.76 \mathrm{~g}$ hydromethanolic crude extract was obtained (see Table 1).

\section{Phytochemistry}

Preliminary qualitative tests were done as per standard test guidelines. These tests revealed the existence of terpenoids, saponins, tannins, flavonoids, glycosides, alkaloids, and phenolic compounds, whereas resins, anthraquinones, and steroids were not detected (See Table 2).

\section{In Vitro $\alpha$-Amylase Inhibitory Activity}

The $\alpha$-amylase inhibitory activity of the acarbose and crude extract are shown in Figure 1. Concentration-dependent inhibition was seen for various concentrations of the tested extract and the standard. Hydromethanolic crude root extract of $D$. barnimiana showed a maximum $\alpha$-amylase enzyme inhibition activity of $67.52 \%$ at $500 \mu \mathrm{g} / \mathrm{mL}$, with $\mathrm{IC}_{50}$ of 4.95 $\mu \mathrm{g} / \mathrm{mL}$. The maximum $\alpha$-amylase inhibition was observed at a high concentration of acarbose $(94.65 \%)$, with $\mathrm{IC}_{5}$ of 2.14 $\mu \mathrm{g} / \mathrm{mL}$.

Table I Quantity and quality of hydromethanolic crude root extract of $D$. barnimiana

\begin{tabular}{|l|l|l|l|}
\hline Solvent & Color and texture of extract & Outcome (g) & Outcome (w/w) \\
\hline $80 \%$ hydromethanol & Dark-brown powder & 406.76 & $40.68 \%$ \\
\hline
\end{tabular}

Abbreviations: gm, gram; w/w, weight by weight.

Table 2 Qualitative phytochemical profiling of hydromethanolic crude root extract of $D$. barnimiana

\begin{tabular}{|l|l|l|l|}
\hline Sample & Phytochemical & Test performed & Result \\
\hline 1 & Alkaloids & Wagner's & + \\
\hline 2 & Anthraquinones & Borntrager's & - \\
\hline 3 & Flavonoids & Alkaline reagent $(\mathrm{NaOH})$ & + \\
\hline 4 & Glycosides & Keller-Killiani & + \\
\hline 5 & Phenolic compounds & Ferric chloride & + \\
\hline 6 & Plant steroids & Liebermann-Burchard & - \\
\hline 7 & Resins & Precipitation & - \\
\hline 8 & Saponins & Froth & + \\
\hline 9 & Tannins & Braemer's & + \\
\hline 10 & Terpenoids & Salkowskis & + \\
\hline
\end{tabular}

Notes: $(+)$ : exists, $(-)$ : does not exist. 


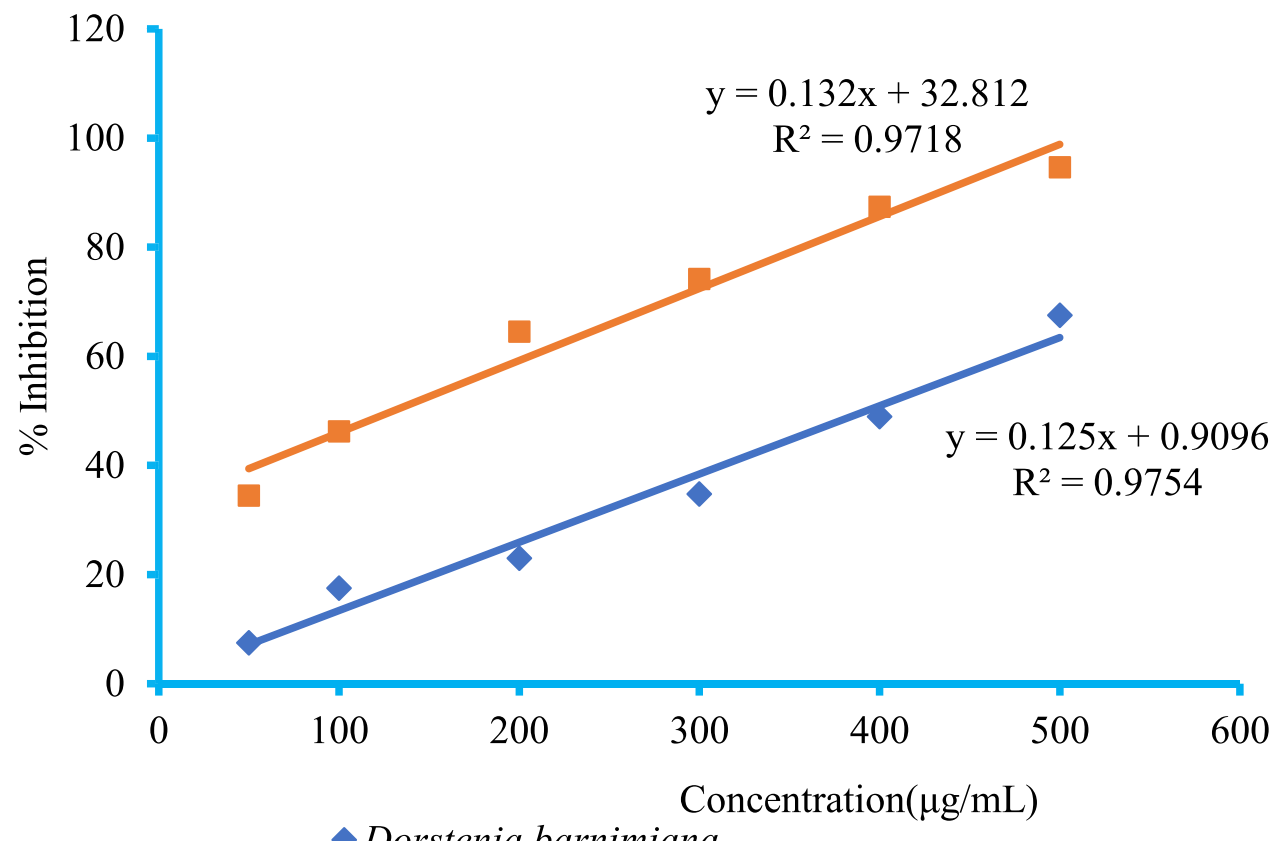

$\rightarrow$ Dorstenia barnimiana

Acarbose

Figure I $\alpha$-Amylase inhibitory activity of crude root extract of Dorstenia barnimiana and acarbose.

Note: Values presented as means $\pm \operatorname{SEM}(n=3)$.

Abbreviation: SEM, standard error of the mean.

\section{Acute Toxicity}

Mortality was not observed at $2,000 \mathrm{mg} / \mathrm{kg}$ during observation, indicating that the $\mathrm{LD}_{50}$ for the extract was $>2,000 \mathrm{mg} /$ $\mathrm{kg}$. The mice did not show any physical or behavioral abnormalities.

\section{Effect on Basal Plasma Glucose}

An investigation in normoglycemic mice made it possible to investigate hypoglycemic effects of the crude extract. Administration of the vehicle (DW $10 \mathrm{~mL} / \mathrm{kg}$ ) did not change plasma-glucose levels significantly during testing. Likewise, administration of hydromethanolic extracts at different test doses did not significantly ameliorate basal plasma-glucose levels compared to the normal control group, whereas the standard agent Glc5 markedly lowered plasma-glucose levels from $129.16 \pm 0.39 \mathrm{mg} / \mathrm{kg}$ to $64.72 \pm 1.95 \mathrm{mg} / \mathrm{kg}$ (see Table 3).

Table 3 Effect of hydromethanolic crude root extract of D. barnimiana on blood-glucose levels in normoglycemic mice

\begin{tabular}{|c|c|c|c|c|c|}
\hline \multirow[t]{2}{*}{ Group } & \multicolumn{5}{|c|}{ Fasting blood glucose $(\mathrm{mg} / \mathrm{dL})$} \\
\hline & 0 & $\mathbf{I}$ & 2 & 4 & 6 \\
\hline DWIO & $129.66 \pm 0.84$ & $128.49 \pm 0.64$ & $127.43 \pm 0.87$ & $|25| .1 \pm \mid .23$ & $123.42 \pm 1.55$ \\
\hline DBI00 & $127.70 \pm 0.50$ & $|26.87 \pm 0.4|^{\beta *}$ & $|25.7| \pm 0.44^{\beta *}$ & $124.57 \pm 0.53^{\beta *}$ & $123.30 \pm 0.58^{\beta *}$ \\
\hline DB200 & $130.12 \pm 0.84$ & $128.82 \pm 0.99^{\beta *}$ & $127.82 \pm 1.04^{\beta *}$ & $127.14 \pm 1.10^{\beta *}$ & $125.99 \pm 1.17^{\beta *}$ \\
\hline DB400 & $128.37 \pm 0.36$ & $128.08 \pm 0.39^{\beta} *$ & $127.26 \pm 0.44^{\beta *}$ & $|26.6| \pm\left. 0.5\right|^{\beta *}$ & $|25.4| \pm 0.35^{\beta *}$ \\
\hline Glc5 & $129.16 \pm 0.39$ & $91.49 \pm 3.21^{\alpha *}$ & $81.07 \pm 3.01^{\alpha *}$ & $68.82 \pm 3.59^{\alpha} *$ & $64.72 \pm 1.95^{\alpha *}$ \\
\hline
\end{tabular}

Notes: Values expressed as means \pm SEM $(n=6)$ and analyzed by one-way ANOVA followed by post hoc Tukey tests. ${ }^{\alpha}$ Compared to negative control; ${ }^{\beta}$ compared to Glc5. $* P<0.001$.

Abbreviations: DB, Dorstenia barnimiana; DW, distilled water; Glc, glibenclamide. 


\section{Effect of Extract on Oral Glucose Tolerance in Mice}

The chief source of energy in animals body is glucose, and the oral glucose-tolerance test (OGTT) enables us to evaluate the body's capacity to use glucose wisely. ${ }^{44}$ A single dose of crude extract was administered to normoglycemic mice to verify its antihyperglycemic activity. OGTTs with $40 \%$ glucose solution resulted in hyperglycemia with a peak of 179.51 $\pm 2.29 \mathrm{mg} / \mathrm{dL} 30$ minutes after administration in the negative-control group, but that peak was significantly averted by both the standard drug (Glc5) and the crude extract at all test doses $(P<0.001$, see Table 4$)$.

\section{Antihyperglycemic Activity in Stz-Induced Diabetic Mice}

BGLs were measured every week in normal and diabetic mice. After induction, diabetic mice showed significant differences in baseline BGLs compared to normal mice $(P<0.001)$, but no significant differences were found among the groups of diabetic mice. Even though diabetic mice were treated for about 2 weeks with DB100 daily and showed BGL reduction to $275.65 \pm 2.62 \mathrm{mg} / \mathrm{dL}$ in the first and $268.22 \pm 3.10 \mathrm{mg} / \mathrm{dL}$ in the second week, this reduction fell short of statistical significance compared to the negative controls, though it had shrunk remarkably by day $21(P<0.01)$ and day $28(P<0.001)$ compared to diabetic controls (see Table 5). Correspondingly, medium and high doses and Glc5 had reduced FBG at 1 week after commencing therapy.

\section{Effect on Body Weight of Diabetic Mice}

Before induction of DM and baseline (3 days after Stz injection), there was no statistically significant weight-loss difference between diabetic and normal mice (see Figure 2). Stz induction had caused a significant loss of weight in

Table 4 Effect of hydromethanolic crude root extract of $D$. barnimiana on blood-glucose levels in mice challenged with oral glucose

\begin{tabular}{|c|c|c|c|c|c|}
\hline \multirow[t]{2}{*}{ Group } & \multicolumn{5}{|c|}{ Fasting glucose level (mg/dL) } \\
\hline & $\mathbf{0}$ & $30^{\prime}$ & $60^{\prime}$ & 90' & 120 \\
\hline DWIO & $|30.56 \pm 0.6|$ & $|79.5| \pm 2.29$ & $168.98 \pm 2.67$ & $158.20 \pm 2.76$ & $140.20 \pm 2.95$ \\
\hline DBI00 & $130.59 \pm 1.46$ & $158.04 \pm\left. 3.0\right|^{\alpha * \beta * \partial_{\Lambda}}$ & $148.88 \pm 2.26^{\alpha * \beta * \partial *}$ & $147.35 \pm 2.11^{\alpha \$ \beta * \partial *}$ & $139.63 \pm 1.14^{\beta * \partial * \varnothing \$}$ \\
\hline DB200 & $133.6 \mid \pm 1.65$ & $|52.92 \pm 2.5|^{\alpha * \beta *}$ & $|42.34 \pm| .26^{\alpha * \beta * \partial *}$ & $140.03 \pm 0.83^{\alpha * \beta * \partial *}$ & $128.27 \pm 1.03^{\alpha \$ \beta * \partial *}$ \\
\hline DB400 & $\mid 30.80 \pm 1.87$ & $143.33 \pm 2.24^{\alpha *}$ & $1 \mid 8.81 \pm 2.35^{\alpha * \beta \wedge}$ & $97.82 \pm 1.33^{\alpha *}$ & $87.47 \pm 0.74^{\alpha *}$ \\
\hline Glc5 & $131.62 \pm 1.85$ & $135.55 \pm 2.08^{\alpha *}$ & $102.28 \pm 4.22^{\alpha *}$ & $94.65 \pm 4.34^{\alpha *}$ & $84.49 \pm 4.70^{\alpha *}$ \\
\hline
\end{tabular}

Notes: Values expressed as means \pm SEM $(n=6)$ and analyzed by one-way ANOVA followed by post hoc Tukey tests. ${ }^{\alpha}$ Compared to negative control; ${ }^{\varnothing}$ compared to DB200 $\mathrm{mg} / \mathrm{kg} ;{ }^{\partial}$ compared to DB400 mg/kg; ${ }^{\beta}$ compared to Glc5. ${ }^{\$} P<0.05 ; \wedge P<0.01 ; * P<0.001$.

Abbreviations: DB, Dorstenia barnimiana; DW, distilled water; Glc, glibenclamide.

Table 5 Antihyperglycemic effect of hydromethanolic crude root extract of $D$. barnimiana in streptozocin-induced diabetic mice

\begin{tabular}{|c|c|c|c|c|c|}
\hline \multirow[t]{2}{*}{ Group } & \multicolumn{5}{|c|}{ Blood glucose $(\mathrm{mg} / \mathrm{dL})$ at weekly intervals } \\
\hline & Day 0 & Day 7 & Day 14 & Day 21 & Day 28 \\
\hline DWIO & $277.17 \pm 2.00^{\varepsilon *}$ & $277.83 \pm 2.85^{\varepsilon *}$ & $275.18 \pm 2.34^{\varepsilon *}$ & $271.97 \pm 2.55^{\varepsilon *}$ & $268.57 \pm 1.64^{\varepsilon *}$ \\
\hline DBI00 & $282.83 \pm 3.21^{\varepsilon *}$ & $275.65 \pm 2.62^{\varnothing * \partial * \beta * \varepsilon *}$ & $268.22 \pm 3.10^{\varnothing * \partial{ }^{\prime} \beta * \varepsilon *}$ & $259.27 \pm 1.84^{\alpha} \wedge^{\partial}{ }^{*} \beta * \varepsilon *$ & $255.4 I \pm 0.78^{\alpha * \partial * \beta * \varepsilon *}$ \\
\hline DB200 & $279.02 \pm 6.39^{\varepsilon *}$ & $256.16 \pm 3.38^{\alpha * \partial * \beta * \varepsilon *}$ & $252.56 \pm 3.06^{\alpha * \partial * \beta * \varepsilon *}$ & $25 \mathrm{I} .0 \mathrm{I} \pm 2.86^{\alpha * \partial * \beta * \varepsilon *}$ & $248.69 \pm 2.86^{\alpha * \partial * \beta * \varepsilon *}$ \\
\hline DB400 & $276.50 \pm 2.51^{\varepsilon *}$ & $220.59 \pm 1.89^{\alpha * \beta * \varepsilon *}$ & $216.38 \pm 2.13^{\alpha * \beta * \varepsilon *}$ & $214.43 \pm 1.98^{\alpha * \beta * \varepsilon *}$ & $2 \mid 4.07 \pm 2.03^{\alpha * \beta * \varepsilon *}$ \\
\hline Glc5 & $276.45 \pm 3.34^{\varepsilon *}$ & $185.56 \pm 2.65^{\alpha * \varepsilon *}$ & $178.82 \pm 2.47^{\alpha * \varepsilon *}$ & $165.94 \pm 1.75^{\alpha * \varepsilon *}$ & $163.75 \pm 1.69^{\alpha * \varepsilon *}$ \\
\hline NC & $129.93 \pm 0.75^{\alpha *}$ & $128.67 \pm 0.38^{\alpha *}$ & $127.57 \pm 0.24^{\alpha *}$ & $126.08 \pm 0.54^{\alpha *}$ & $125.56 \pm 0.62^{\alpha *}$ \\
\hline
\end{tabular}

Notes: Values expressed as means \pm SEM $(n=6)$ and analyzed by one-way ANOVA followed by post hoc Tukey tests. ${ }^{\alpha}$ Compared to negative control; ${ }^{\varnothing}$ compared to DB200 $\mathrm{mg} / \mathrm{kg} ;{ }^{2}$ compared to DB400 mg/kg; ${ }^{\beta}$ compared to Glc5; ${ }^{\varepsilon}$ compared to normal control. ${ }^{\wedge} P<0.01 ; * P<0.001$.

Abbreviations: DB, Dorstenia barnimiana; DW, distilled water; Glc, glibenclamide; NC, normal control (pretreatment significantly brought down the volume of BGL). 


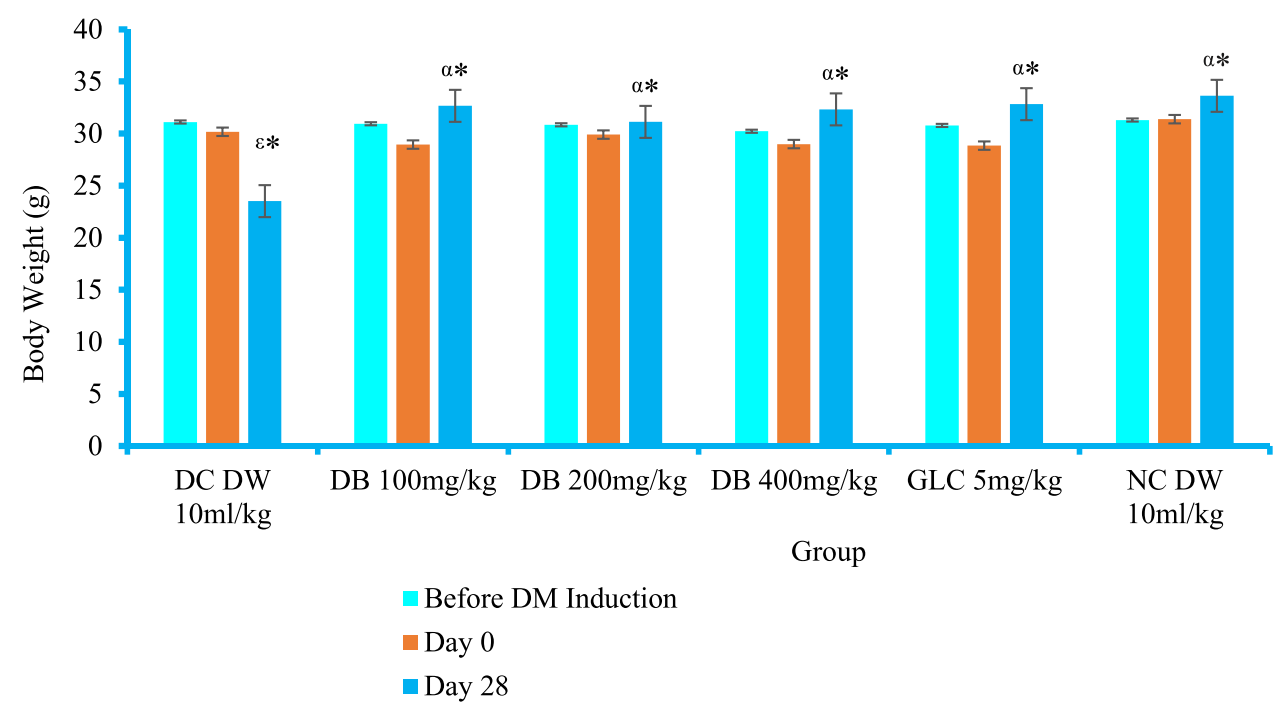

Figure 2 Effect of Dorstenia barnimiana crude extract on body weight of diabetic mice in Stz-induced model.

Notes: Values expressed as means \pm SEM ( $n=6$ mice in each group) and analyzed by one-way ANOVA followed by post hoc Tukey tests. ${ }^{\alpha}$ Compared to negative control; ${ }^{\varepsilon}$ compared to NC. $* P<0.001$.

Abbreviations: DB, Dorstenia barnimiana; DC, diabetic control; DM, diabetes mellitus; DW, distilled water; Glc, glibenclamide; NC, normal control.

diabetic controls by days $7(P<0.05), 14(P<0.001), 21(P<0.001)$, and $28(P<0.001)$ compared to normal controls. In the first week of therapy, neither the crude extract nor the standard agent was able to retard the weight loss. Significant bodyweight increments were recorded for DB200 $(P<0.05)$, DB400 $(P<0.01)$, and Glc5 $(P<0.01) 2$ weeks after treatment had commenced compared to the diabetic control group. Similarly significant body-weight recovery was recorded for DB100 $(P<0.05)$, DB200 $(P<0.001)$, DB400 $(P<0.001)$, and Glc5 $(P<0.001)$ on day 21 compared to diabetic controls. All doses of the crude extract and Glc5 showed an significant $(P<0.001)$ increment in body weight after 28 days of therapy (see Table 6).

\section{Effect on Serum-Lipid Profile of Diabetic Mice}

The DB100 group showed significant reductions in serum levels of TC $(P<0.001)$, TGs $(P<0.01)$, LDL-C $(P<0.01)$, and VLDL-C $(P<0.05)$, but failed to reach statistical significance for HDL-C compared to diabetic controls (see Table 7). Likewise, DB200-treated groups showed significant reductions in serum levels of TC $(P<0.001)$, TGs $(P<0.001)$, LDL-C $(P<0.001)$, and VLDL-C $(P<0.01)$, but did not show a significant increase in serum HDL-C compared to diabetic

Table 6 Effect of crude extract on body weight of diabetic mice

\begin{tabular}{|c|c|c|c|}
\hline \multirow[t]{2}{*}{ Group } & \multicolumn{3}{|c|}{ Body weight (g) } \\
\hline & Day 7 & Day I4 & Day 21 \\
\hline DWIO & $27.66 \pm 0.69^{\varepsilon \$}$ & $25.53 \pm 0.64^{\varepsilon *}$ & $25.33 \pm 0.56^{\varepsilon *}$ \\
\hline DBI00 & $27.79 \pm 0.78$ & $27.91 \pm 0.56$ & $28.12 \pm 0.53^{\alpha \$ \beta \$ \partial \$}$ \\
\hline DB200 & $28.22 \pm 0.72$ & $28.77 \pm 0.54^{\alpha \Phi}$ & $29.75 \pm 0.55^{\alpha *}$ \\
\hline DB400 & $28.46 \pm 0.4 I$ & $29.93 \pm 0.40^{\alpha_{\Lambda}}$ & $30.74 \pm 0.4 I^{\alpha *}$ \\
\hline Glc5 & $27.84 \pm 0.39$ & $30.05 \pm 0.79^{\alpha_{\Lambda}}$ & $30.89 \pm 0.53^{\alpha *}$ \\
\hline NC & $31.05 \pm 1.27^{\alpha \$}$ & $31.53 \pm 1.26^{\alpha} *$ & $32.56 \pm 0.90^{\alpha} *$ \\
\hline
\end{tabular}

Notes: Values expressed as means \pm SEM $(n=6)$ and analyzed by one-way ANOVA followed by post hoc Tukey tests. ${ }^{\alpha}$ Compared to negative control; ${ }^{2}$ compared to DB400 $\mathrm{mg} / \mathrm{kg} ;{ }^{\beta}$ compared to Glc5; ${ }^{\varepsilon}$ compared to NC. ${ }^{\$} P<0.05 ; \wedge P<0.01 ; * P<0.001$.

Abbreviations: DB, Dorstenia barnimiana; DW, distilled water; Glc, glibenclamide; NC, normal control. 
Table 7 Effect of crude extract on serum-lipid levels in diabetic mice

\begin{tabular}{|c|c|c|c|c|c|}
\hline \multirow[t]{2}{*}{ Group } & \multicolumn{5}{|c|}{ Serum Lipid Level (mg/dL) } \\
\hline & TC & TGs & LDL-C & VLDL-C & HDL-C \\
\hline DWIO & $174.07 \pm 2.98^{\varepsilon *}$ & $119.02 \pm 3.03^{\varepsilon *}$ & || $5.21 \pm 3.34^{\varepsilon *}$ & $23.80 \pm 1.49^{\varepsilon *}$ & $35.06 \pm 0.86^{\varepsilon *}$ \\
\hline DBI00 & $148.16 \pm 3.92^{\alpha * \beta * \varnothing_{\wedge} \partial *}$ & $101.62 \pm 3.10^{\alpha \wedge \beta * \theta_{\Lambda} \partial_{\Lambda}}$ & $90.57 \pm 0.38^{\alpha \wedge \beta * \partial \$}$ & $20.32 \pm 0.41^{\alpha \$ \beta * \partial \$}$ & $37.27 \pm 0.54$ \\
\hline DB200 & $130.17 \pm 1.18^{\alpha *}$ & $85.31 \pm 3.18^{\alpha *}$ & $69.80 \pm 0.56^{\alpha * \beta *}$ & $17.06 \pm 0.57^{\alpha_{\wedge} \beta_{\Lambda}}$ & $43.31 \pm 1.02^{\beta_{\Lambda} \theta_{\Lambda} \partial_{\Lambda}}$ \\
\hline DB400 & $127.04 \pm 0.69^{\alpha *}$ & $83.59 \pm 1.54^{\alpha *}$ & $65.74 \pm 1.54^{\alpha * \beta *}$ & $16.72 \pm 0.62^{\alpha *}$ & $44.58 \pm 0.57^{\alpha *}$ \\
\hline Glc5 & $122.12 \pm 4.20^{\alpha}{ }_{*}$ & $81.09 \pm 2.47^{\alpha *}$ & $60.92 \pm 0.67^{\alpha *}$ & $\mid 6.22 \pm 1.01^{\alpha *}$ & $44.98 \pm 2.29^{\alpha} *$ \\
\hline NC & $107.43 \pm 3.25^{\alpha *}$ & $96.75 \pm 2.33^{\alpha *}$ & $40.73 \pm 1.05^{\alpha *}$ & $19.35 \pm 0.42^{\alpha *}$ & $47.35 \pm 0.23^{\alpha *}$ \\
\hline
\end{tabular}

Notes: Values expressed as means \pm SEM $(n=6)$ and analyzed by one-way ANOVA followed by post hoc Tukey tests. ${ }^{\alpha}$ Compared to negative control; ${ }^{\varnothing}$ compared to DB200 $\mathrm{mg} / \mathrm{kg} ;{ }^{\partial}$ compared to DB400 mg/kg; ${ }^{\beta}$ compared to Glc5; ${ }^{\varepsilon}$ compared to $\mathrm{NC} .{ }^{\$} \mathrm{P}<0.05 ; \wedge \mathrm{P}<0.0 \mathrm{I} ;{ }^{*} \mathrm{P}<0.00 \mathrm{I}$.

Abbreviations: DB, Dorstenia barnimiana; DW, distilled water; Glc, glibenclamide; NC, normal control.

controls. However, the group of mice treated with the highest dose and standard agent for 28 days showed a significant decrease in TC, TGs, LDL-C, and VLDL-C and increased HDL-C markedly compared to diabetic controls.

\section{Discussion}

DM is a global public health challenge, especially with current medications being incapable of averting diabetic complications. Therefore, contemporary research aimed at identifying phytomedicines is needed for new preventive and therapeutic approaches. In Addis Ababa, Ethiopia, D. barnimiana tubes are sold for the treatment of a variety of diseases, including DM. ${ }^{34}$ In this study, before advancing to the animal study, the antidiabetic effect of D. barnimiana root was investigated in vitro by ascertaining its $\alpha$-amylase inhibition activity. The pancreas is the principal organ engaged in detecting the body's energy and dietary states through the concentration of BG. When the BGL shifts, the pancreas responds via monitoring the release of insulin, $\alpha$-amylase, and other pancreatic enzymes. Pancreatic $\alpha$ glucosidase and $\alpha$-amylase inhibition is an efficient approach to decrease levels of postprandial hyperglycemia through starch-breakdown control. This is a key approach in the management of type 2 diabetic patients and prediabetics. ${ }^{45} \alpha$ Amylase inhibition assays were done to verify the $\alpha$-amylase inhibition effect of $D$. barnimiana by employing acarbose as a standard reference. Acarbose is a modern medicine for managing DM by inhibiting the $\alpha$-amylase and $\alpha$-glucosidase activity that converts starch into glucose, ${ }^{46}$ whereas the plant extract acts as a natural inhibitor. The results showed that the plant may have antidiabetic properties, since there was no appreciable discrepancy between $\mathrm{IC}_{50}$ values of the standard drug (acarbose) and natural inhibitor (extract) at $2.14 \mu \mathrm{g} / \mathrm{mL}$ vs $4.95 \mu \mathrm{g} / \mathrm{mL}$, respectively. Flavonoids from Dorstenia spp. (eg, D. psilurus), such as artelasticin, have been found to be $\alpha$-glucosidase inhibitors, thereby reducing the risk of hyperglycemia by expanding the carbohydrate-absorption period. ${ }^{47}$ The roots of $D$. drakena have antisecretory effects, ${ }^{48}$ and as such, $D$. barnimiana may also be beneficial in decreasing the secretion of pancreatic enzymes.

The in vitro finding establishes the extract's candidacy for further analysis of its antidiabetic activity in in vivo models. The effect of the extract on BGL was evaluated by initiating normoglycemic, oral glucose tolerance, and Stzinduced diabetic mice models. In the acute oral toxicity study at the limit dose of 2,000 $\mathrm{mg} / \mathrm{kg}$, D. barnimiana root extract remained atoxic during the study period. This safety profile is congruent with a report by Derebe et al. ${ }^{31}$ Normoglycemic models provide clues to the mechanisms of action of natural remedies. ${ }^{21}$ The results from the normoglycemic studies implied that the hydromethanolic crude extract of D. barnimiana had no hypoglycemic activity compared to normal controls, suggesting a lower risk of hypoglycemia for individuals in a euglycemic state. These findings are comparable to Alene et al. ${ }^{49}$

A drug that is efficient in DM will have the capacity to control dysglycemia through different hepatic and extrahepatic mechanisms. The capacity of the extract to prevent hyperglycemia can be determined with the OGTT. ${ }^{50}$ Interestingly, in this model, even the lowest dose of the crude extract resulted in a significant reduction in BGL after 30 minutes. This 
shows that the extract has the ability to enhance glucose regulatory mechanisms, indicating its potential for minimizing meal-related hyperglycemia and complications of DM. It was observed that the extract exerted its action in a dosedependent manner, and the highest dose (DB400) produced the maximum activity in all tests undertaken. The lowest dose (DB100) appeared to be ineffective in reducing the resurgence of BGL in glucose-loaded animals significantly at 2 hours. This may be due to the lower concentration of the active principles in the serum attained initially associated with the low dose administration or may be due to rapid elimination of the drug from the body.

Stz causes DM in experimental animals due to its higher inductive rate and selective toxicity. ${ }^{49}$ After IP or IV administration, it enters pancreatic $\beta$ cells through the GLUT2 transporter. Accumulation of Stz in $\beta$ cells results in cell death via methylating DNA, which depletes the production of insulin. ${ }^{51}$ Insulin deficiency disrupts the metabolism of carbohydrates, fats, and proteins in liver, adipose, and muscle tissue thereby raising levels of glucose, cholesterol, nitrogen balance, muscle wasting, and weight loss. ${ }^{21}$ Chemically induced DM is able to mimic the physiological and biochemical derangements in the actual disease. ${ }^{52}$ Oral administration of the extract resulted in appreciable improvement in glucose homeostasis in diabetic mice. As shown in Table 6, the crude extract possessed antihyperglycemic activity when administered to Stz-induced diabetic mice at all test doses. In light of the results obtained from the Stz-induced model, it could be deduced that the roots of D. barnimiana have authentic antidiabetic activity and that their use in traditional medicine to control DM may be justified.

DM is also distinguished by dyslipidemia, which accounts for elevated levels of TC, TGs, and LDL-C and lower levels of HDL-C and is a major cause of cardiovascular problems. ${ }^{53}$ Insulin triggers lipoprotein lipase, which can metabolize TGs and VLDL-C. In diabetic patients, lipoprotein lipase is less active due to insulin deficiency, and this can lead to development of diabetic dyslipidemia. ${ }^{35}$ The serum-lipid profile of the diabetic control group revealed a significant increase in serum TGs, TC, VLDL-C, LDL-C and decrease of HDL-C compared to normal controls $(P<0.001)$. Interestingly, treatment with the extract resulted in significant improvements in lipid profile: at 4 weeks, serum TC, TGs, VLDL-C, and LDL-C had reduced and were able to enhance HDL-C levels. These findings also correlate with those of Tsofack et $\mathrm{al}^{47}$ and Jyothsna et $\mathrm{al},{ }^{44}$ who (respectively) reported that D. picta and Cinnamomum zeylanicum reduced cholesterol and TGs in experimentally induced diabetic rats. This activity of the plant extract may be related to the presence of secondary metabolites implicated in the antihyperlipidemic activity of plant extracts.

Several plant constituents (such as flavonoids) detected in D. barnimiana are known to decrease TGs, TC, LDL-C, and VLDL-C. ${ }^{47,54}$ Absorption of free fatty acids and free cholesterol can be inhibited by intervening the enzymatic activity of pancreatic lipase and pancreatic cholesterol esterases, thereby preventing hyperlipidemia related to DM. The antihyperlipidemic effects of the extract could be attributed to inhibition of those enzymes. In addition to their hypolipidemic properties, flavonoids have been shown to decrease serum glycated hemoglobin levels. ${ }^{55}$ Herein, even though all doses of the crude extract were able to modify serum-cholesterol levels, the highest dosage (DB400) exhibited the best antihyperlipidemic activity. The antihyperlipidemic activity of medicinal plants points to new directions for the development of antidiabetic agents with multiple therapeutic targets. ${ }^{56}$

Weight loss is another cardinal feature of DM. It is due to insulin insufficiency, which results in depletion in protein synthesis and in turn reduced amino-acid uptake by tissue, resulting in lipolysis and proteolysis in adipose tissue. ${ }^{15}$ In this study, there was a genuine weight reduction in Stz-induced diabetic mice. However, after treatment with extract, the weight lost was redeemed. This prevention of weight loss is in line with other studies done on the same plant. At all tested doses, the significantly prevented weight loss in a dose-dependent manner compared to negative controls on the 4day suppression and curative tests, but not the prophylaxis test. ${ }^{31}$ The capacity of $D$. barnimiana extracts to prevent significant weight loss may be attributed to the bioactive compounds that suppresses oxidative stress from free radicals generated via hyperglycemia.

In the present findings, the root extract showed an antihyperglycemic effect in Stz-induced diabetic mice without causing hypoglycemia in normoglycemic mice while Glc showed both hypoglycemic and antihyperglycemic effects in normoglycemic and Stz-induced diabetic mice. As a result, the mechanism of action of root extracts of D. barnimiana in the treatment of diabetic mice is unquestionably different from the standard drug Glc, which acts by increasing insulin secretion from the pancreas and should be used with caution in patients with cardiovascular disease or in elderly patients, in whom hypoglycemia would be especially dangerous. ${ }^{57}$ However, wide-ranging pharmacological and biochemical 
research is required to address the detailed mechanisms and active principles responsible for the antihyperglycemic effects observed.

Preliminary qualitative analysis was part of our work which revealed the presence of secondary metabolites like terpenoids, alkaloids, flavonoids, phenols, saponins, tannins, and cardiac glycosides, whereas resins, anthraquinones, and steroids were not detected, similar to other Dorstenia spp., eg, D. mannii ${ }^{58}$ and D. picta. ${ }^{47}$ However, terpenoids were not detected in $D$ barnimiana in a qualitative study conducted by Derebe et al. From the present plant-extraction yield determination, there was no marked difference from a previously reported yield $(40.68 \% \mathrm{vs} 44.3 \% \mathrm{w} / \mathrm{w}) .{ }^{31}$ This discrepancy in outcomes might be explained by ecological, edaphic, or climate disparities.

Secondary metabolites with antidiabetic activity include alkaloids, glycosides, galactomannan gum, polysaccharides, peptidoglycans, hypoglycans, guanidine, phytosterols, flavonoids, phenols, saponins, tannins, carbohydrates, polyphenol, glycopeptides, terpenoids, amino acids, and inorganic ions. ${ }^{59-61}$ Tannins are excellent free-radical scavengers. ${ }^{62}$ Tannins also inhibit the activity of digestive enzymes, such as trypsin and amylase. ${ }^{63}$ Saponins also exhibit hypoglycemic effects via several means such as rehabilitation of insulin production and release, insulin-receptor sensitivity, reduction of hepatic gluconeogenesis, activation of glycogen production, ameliorative effects on gluconeogenesis, inhibition of $\alpha$ glucosidase activity, and inhibition of mRNA expression of glycogen phosphorylase and glucose- 6 phosphatases. ${ }^{64}$ Likewise, flavonoids from $D$. psilurus can activate, thereby stimulating glucose uptake, inhibiting glucose production, and lowering hyperglycemia. ${ }^{47}$ Prenylated flavonoids isolated from $D$. mannii such as 6,8-diprenyleriodictyol, dorsmanin $\mathrm{C}$, and dorsmanin F, are potent scavengers of the stable free radical DPPH. ${ }^{65}$ D. barteri, D. convexa, D. foetida, D. psilurus, and $D$. ciliate also have proven antioxidant activity, generally related to the presence of flavonoids and other phenolic compounds. ${ }^{66}$ Therefore, the activity of this plant extract against DM might be due to the content of these phenolic compounds.

\section{Conclusion}

The present glycemic study found that the hydromethanolic crude root extract of $D$. barnimiana has potential antidiabetic and antihyperlipidemic effect, which confirms the plausibility of traditional claims. However, before recommending it for use, further studies should be conducted with relevant models to elucidate its mechanisms of action and confirm its efficacy and safety profile.

\section{Recommendations}

This study clearly backs the traditional claims of this extract's therapeutic properties. As such, further in-depth investigation is needed using other relevant models through histopathological examinations of the pancreas for more comprehensive evidence. Isolation and characterization of the active components to isolate and identify the active principle(s) responsible for its ethnopharmacological activity and to elucidate the exact mechanism action of this plant using advanced technologies like HPLC and GMSC is needed.

\section{Limitations}

- This was a preliminary study that aimed to validate only the antidiabetic potential of the crude extracts of plant materials.

- The glucose-lowering effects of $D$ barnimiana might be mediated, at least partially, through its antioxidant effect, which need further study.

- Consequently, it was necessary to perform subchronic and chronic toxicological investigation of this plant empirically, in order to avoid the risk of side effects related to phytotherapy.

- Species variation would limit a straightforward extrapolation of the findings of this study to humans.

\section{Abbreviations}

FBG, fasting blood glucose; HDL, high-density lipoprotein; LDL, low-density lipoprotein; OGTT, oral glucose-tolerance test; Stz, streptozotocin; TC, total cholesterol; TGs, triglycerides. 


\section{Data Sharing}

All the data used to support the findings of this study are available from the corresponding author upon reasonable request.

\section{Ethics}

The experimental animals were handled and cared for in the experimental procedures according to the local ethical and internationally accepted laboratory animal use, care and welfare guidelines such as Basel declaration, ${ }^{67}$ International Council for Laboratory Animal Science ethical guidelines, ${ }^{68}$ and the EU directive ${ }^{69}$ on the protection of animals used for scientific purposes. This study was approved by the ethical clearance which was requested and obtained from the research and ethical review committee of College of Health Sciences, Debre Tabor University with reference code number of SOP12/173/21.

\section{Acknowledgments}

Most importantly, we would like to thank the Debre Tabor University, College of Medicine and Health Sciences, School of Pharmacy, Department of Pharmacology for its indispensable support, and involvement in different aspects from the beginning to the finalization of the work. Secondly, we would like to thank Dr Getinet Masresha for the authentication of the plant material.

\section{Author Contributions}

All the authors have been involved in the design, conducting the research, data analysis, drafting or revising the article and write-up of the study. We have agreed on the journal to which the article was submitted, given final approval of the version to be published, and agreed to be accountable for all aspects of the work.

\section{Funding}

No source of funding.

\section{Disclosure}

The authors declare that they have no conflicts of interest for this work.

\section{References}

1. Punthakee Z, Goldenberg R, Katz P. Definition, classification and diagnosis of diabetes, prediabetes and metabolic syndrome. Can J Diabetes. 2018;42:S10-5. doi:10.1016/j.jcjd.2017.10.003

2. Fattaheian-Dehkordi S, Hojjatifard R, Saeedi M, Khanavi M, Mancianti F. A review on antidiabetic activity of Centaurea spp.: a new approach for developing herbal remedies. Evid Based Complement Altern Med. 2021;2021:1-23. doi:10.1155/2021/5587938

3. Siddiqui AA, Siddiqui SSA, Ahmad S, et al. Diabetes: mechanism, pathophysiology and management-A review. Int J Drug Dev Res. 2013;5 (2):1-23.

4. Baynest HW. Classification, pathophysiology, diagnosis and management of diabetes mellitus. J Diabetes Metab. 2015;06(05). doi:10.4172/21556156.1000541

5. Skyler JS, Bakris GL, Bonifacio E, et al. Differentiation of diabetes by pathophysiology, natural history, and prognosis. Diabetes. 2017;66(2):241255. doi: $10.2337 / \mathrm{db} 17$-ti02

6. Olukayode Ajayi G, Mary Edamisan O, Titilayo Obayemi P, Namesegua Elegbeleye E, Uchechukwu Obi E. Phytoconstituents and antidiabetic activity of Vernonia amygdalina (Asteraceae) in streptozotocin-induced diabetic rats. Int J Biochem Bioinforma Biotechnol Stud. 2021;6(1):1-16.

7. Aynalem SB, Zeleke AJ. Prevalence of diabetes mellitus and its risk factors among individuals aged 15 years and above in Mizan-Aman Town, Southwest Ethiopia, 2016: a cross sectional study. Int J Endocrinol. 2018;2018:1-7. doi:10.1155/2018/9317987

8. Alqathama A, Alluhiabi G, Baghdadi H, et al. Herbal medicine from the perspective of type II diabetic patients and physicians: what is the relationship? BMC Complement Med Ther. 2020;20(1):65. doi:10.1186/s12906-020-2854-4

9. Tafesse TB, Hymete A, Mekonnen Y, Tadesse M. Antidiabetic activity and phytochemical screening of extracts of the leaves of Ajuga remota Benth on alloxan-induced diabetic mice. BMC Complement Altern Med. 2017;17(1):1-9. doi:10.1186/s12906-017-1757-5

10. Saraei P, Asadi I, Kakar MA, Moradi-Kor N. The beneficial effects of metformin on cancer prevention and therapy: a comprehensive review of recent advances. Cancer Manag Res. 2019;11:3295-3313. doi:10.2147/CMAR.S200059

11. Govindappa M. A review on role of plant (s) extracts and its phytochemicals for the management of diabetes. J Diabetes Metab. 2015;6(7):1-38. doi:10.4172/2155-6156.1000565

12. Rupeshkumar M, Kavitha K, Haldar PK. Role of herbal plants in the diabetes mellitus therapy: an overview. Int J Appl Pharm. 2014;6(3):1-3. 
13. Arika WM, Abdirahman YA, Mawia MA, et al. In vivo antidiabetic activity of the aqueous leaf extract of Croton macrostachyus in alloxan induced diabetic mice. Pharm Anal Acta. 2015;6(11):1-5. doi:10.4172/2153-2435.1000447

14. Wakene W, Asmamaw S, Kahaliw W. Evaluation of antidiabetic and antioxidant activity of leaf extract and solvent fractions of hypoestes forskaolii (Val) (Acanthaceae) in mice. J Exp Pharmacol. 2021;13:859-872. doi:10.2147/JEP.S318696

15. Taye GM, Bule M, Gadisa DA, Teka F, Abula T. In vivo antidiabetic activity evaluation of aqueous and $80 \%$ methanolic extracts of leaves of thymus schimperi (Lamiaceae) in alloxan-induced diabetic mice. Diabetes Metab Syndr Obes Targets Ther. 2020;13:3205-3212. doi:10.2147/ DMSO.S268689

16. Ayele AG, Kumar P, Engidawork E. Antihyperglycemic and hypoglycemic activities of the aqueous leaf extract of Rubus Erlangeri Engl (Rosacea) in mice. Metab Open. 2021;11:100118. doi:10.1016/j.metop.2021.100118

17. Kifle ZD, Enyew EF. Evaluation of in vivo antidiabetic, in vitro $\alpha$-amylase inhibitory, and in vitro antioxidant activity of leaves crude extract and solvent fractions of Bersama abyssinica Fresen (Melianthaceae). J Evid Based Integr Med. 2020;25:2515690X2093582. doi:10.1177/ 2515690X20935827

18. Belayneh YM, Birru EM. Antidiabetic activities of hydromethanolic leaf extract of Calpurnia aurea (Ait.) Benth. Subspecies aurea (Fabaceae) in mice. Evid Based Complement Altern Med. 2018;2018:1-9. doi:10.1155/2018/3509073

19. Shewamene Z, Abdelwuhab M, Birhanu Z. Methanolic leaf extract of Otostegia integrifolia Benth reduces blood glucose levels in diabetic, glucose loaded and normal rodents. BMC Complement Altern Med. 2015;15(1):1-7. doi:10.1186/s12906-015-0535-5

20. Derebe D, Wubetu M, Alamirew A. Hypoglycemic and antihyperglycemic activities of $80 \%$ methanol root extract of acanthus polystachyus delile (Acanthaceae) in type 2 diabetic rats. Clin Pharmacol Adv Appl. 2020;12:149-157. doi:10.2147/CPAA.S273501

21. Melaku BC, Amare GG. Evaluation of antidiabetic and antioxidant potential of hydromethanolic seed extract of datura stramonium Linn (Solanaceae). J Exp Pharmacol. 2020;12:181-189. doi:10.2147/JEP.S258522

22. Mekuria AB, Geta M, Birru EM, Gelayee DA. antimalarial activity of seed extracts of Schinus molle against Plasmodium berghei in mice. J Evid Based Integr Med. 2021;26:2515690X2098428. doi:10.1177/2515690X20984287

23. Kifle ZD, Yesuf JS, Atnafie SA. Evaluation of in vitro and in vivo anti-diabetic, anti-hyperlipidemic and anti-oxidant activity of flower crude extract and solvent fractions of hagenia abyssinica (Rosaceae). J Exp Pharmacol. 2020;12:151-167. doi:10.2147/JEP.S249964

24. Alema NM, Periasamy G, Sibhat GG, Tekulu GH, Hiben MG. Antidiabetic activity of extracts of Terminalia brownii fresen. Stem bark in mice. $J$ Exp Pharmacol. 2020;12:61-71. doi:10.2147/JEP.S240266

25. Wang L, Wu H, Deng Y, et al. FTZ ameliorates diabetic cardiomyopathy by inhibiting inflammation and cardiac fibrosis in the streptozotocininduced model. Evid Based Complement Altern Med. 2021;2021:1-16. doi:10.1155/2021/5582567

26. Chen Y, Lin X, Zheng Y, Yu W, Lin F, Zhang J. Dendrobium mixture ameliorates diabetic nephropathy in db/db mice by regulating the TGF- $\beta$ 1/ smads signaling pathway. Evid Based Complement Altern Med. 2021;2021:1-11. doi:10.1155/2021/9931983

27. Yineger H, Kelbessa E, Bekele T. A study of ethno botany of medicinal plants and floristic composition of the dry Afromontane forest at Bale Mountains National Park. SINET Ethiop J Sci. 2008;31(2):103-120.

28. Bishai D. Review of ethnobotanical and ethnopharmacological evidences of some Ethiopian medicinal plants traditionally used for the treatment of cancer. Ethiop J Health Dev. 2017;31(3):161-187. doi:10.4314/ejhd.v31i3

29. Teklehaymanot T. An ethnobotanical survey of medicinal and edible plants of Yalo Woreda in Afar regional state, Ethiopia. J Ethnobiol Ethnomed. 2017;13(1). doi:10.1186/s13002-017-0166-7

30. Negesse GS, Lulekal E. Use and conservation of traditional medicinal plants in Alelitu Woreda North Shewa, Oromia Region Ethiopia. 2019.

31. Derebe D, Wubetu M, Alamirew A. Evaluation of antimalarial activity of $80 \%$ methanolic root extract of dorstenia barnimiana against plasmodium berghei-infected mice. Clin Pharmacol Adv Appl. 2021;13:157-167. doi:10.2147/CPAA.S313847

32. Aphrodite C, Johanns M, Beaufay C, et al. Two isoprenylated flavonoids from Dorstenia psilurus activate AMPK, stimulate glucose uptake, inhibit glucose production and lower glycemia. Biochem J. 2019;476(24):3687-3704. doi:10.1042/BCJ20190326

33. Franke K, Porzel A, Masaoud M, Nter Adam G, Rgen Schmidt J. Furanocoumarins from Dorstenia gigas. Phytochemistry. 2001;56:611-621. doi:10.1016/S0031-9422(00)00419-2

34. Abegaz BM, Ngadjui BT, Dongo E, Bezabih MT. Chemistry of the genus Dorstenia. Curr Org Chem. 2000;4:1079-1090. doi:10.2174/ 1385272003375905

35. Belayneh YM, Birhanu Z, Birru EM, Getenet G. Evaluation of in vivo antidiabetic, antidyslipidemic, and in vitro antioxidant activities of hydromethanolic root extract of datura stramonium L. (Solanaceae). J Exp Pharmacol. 2019;11:29-38. doi:10.2147/JEP.S192264

36. Shetty SB, Mahin-Syed-Ismail P, Varghese S, et al. Antimicrobial effects of Citrus sinensis peel extracts against dental caries bacteria: an in vitro study. J Clin Exp Dent. 2016;8:70-77.

37. Alhadi EA, Khalid HS, Alhassan MS, Kabbashi AS, Noo MO. Antimicrobial and phytochemical screening of Cordia africana in Sudan. World $J$ Pharm Res. 2015;4:257-269.

38. OECD. Organization for Economic Cooperation and Development Guideline Test No. 425: Acute Oral Toxicity: Up-And-Down Procedure(UDP). Paris, France: OECD Publishing; 2008:1-21.

39. Furman BL. Streptozotocin-induced diabetic models in mice and rats. Curr Protoc Pharmacol. 2015;70(1):5.47.1-5.47.20. doi:10.1002/ 0471141755.ph0547s70

40. Deeds MC, Anderson JM, Armstrong AS, et al. Single dose streptozotocin-induced diabetes: considerations for study design in islet transplantation models. Lab Anim. 2011;45(3):131-140. doi:10.1258/la.2010.010090

41. Tamiru W, Engidawork E, Asres K. Evaluation of the effects of $80 \%$ methanolic leaf extract of Caylusea abyssinica (fresen.) fisch. \& Mey. on glucose handling in normal, glucose loaded and diabetic rodents. BMC Complement Altern Med. 2012;12:1-7. doi:10.1186/1472-6882-12-151

42. Demoz MS, Gachoki KP, Mungai KJ, Negusse BG. Evaluation of the anti-diabetic potential of the methanol extracts of aloe camperi, meriandra dianthera and a polyherb. J Diabetes Mellit. 2015;05(04):267-276. doi:10.4236/jdm.2015.54033

43. Vogel HG. Drug Discovery and Evaluation: Pharmacological Assays. Springer Science \& Business Media; 2002.

44. Jayaraju KJ, Ishaq BM. Evaluation of antidiabetic activity of a novel polyherbal preparation against streptozotocin induced diabetes rat model. $J$ Pharm Res Int. 2021;42-54. doi:10.9734/jpri/2021/v33i26a31470

45. Tijjani H, Imam SA. Inhibition of haemoglobin glycosylation, glucose uptake and in vitro antidiabetic activities of solvent fractions from Daucus carota seed. Ann Sci Technol. 2021. doi:10.2478/ast-2021-0004 
46. Nagoor Gunny AA, Qing LZ, Che Mat MH. In-vitro antioxidant and antidiabetic activity of curcuma xanthorrhiza. In: AIP Conference Proceedings. American Institute of Physics Inc.; 2021. doi:10.1063/5.0044369.

47. Tsofack N, Théophile D, Djomeni D, Désiré P. Antidiabetic activities of methanol-derived extract of Dorstenia picta twigs in normal and streptozotocin-induced diabetic rats. Asian J Tradit Med. 2007;2(4):140-148.

48. Kyerematen G, Medina E, Saavedra D, Sandberg F. Antidiarrhoeal properties of Dorstenia drakena L. Acta Pharm Suec. 1985;22(1):31-36.

49. Alene M, Abdelwuhab M, Belay A, Yazie TS. Evaluation of antidiabetic activity of Ajuga integrifolia (Lamiaceae) root extract and solvent fractions in mice. Evid Based Complement Altern Med. 2020;2020:1-11. doi:10.1155/2020/6642588

50. Rashid U, Khan MR. Phytochemicals of Periploca aphylla Dcne. ameliorated streptozotocin-induced diabetes in rat. Environ Health Prev Med. 2021;26. doi:10.1186/s12199-021-00962-0

51. King AJF. The use of animal models in diabetes research. Br J Pharmacol. 2012;166(3):877-894. doi:10.1111/j.1476-5381.2012.01911.x

52. Ansari MN, Saeedan AS, Bajaj S, Singh L. Evaluation of antidiabetic and hypolipidemic activity of Barleria cristata Linn. leaves in alloxan-induced diabetic rats. 3 Biotech. 2021;11(4). doi:10.1007/s13205-021-02728-5

53. Sharma A, Kaur R, Kaur J, Garg S, Bhatti R, Kaur A. An endophytic Schizophyllum commune Fr. exhibits in-vitro and in-vivo antidiabetic activity in streptozotocin induced diabetic rats. AMB Express. 2021;11(1). doi:10.1186/s13568-021-01219-3

54. Pérez Gutiérrez RM, Muñiz-Ramirez A, Garcia-Campoy AH, Mota Flores JM. Evaluation of the antidiabetic potential of extracts of Urtica dioica, Apium graveolens, and Zingiber officinale in mice, zebrafish, and pancreatic $\beta$-cell. Plants. 2021;10(7). doi:10.3390/plants10071438

55. Yazid F, Salim SO, Rahmadika FD, et al. Antidiabetic effects of Tithonia diversifolia and Malus domestica leaf extracts in alloxan-induced Sprague Dawley rats. Syst Rev Pharm. 2021;12(1):1630-1638.

56. Wasana KGP, Attanayake AP, Jayatilaka KA, Weerarathna TP. Antidiabetic activity of widely used medicinal plants in the Sri Lankan traditional healthcare system: new insight to medicinal flora in Sri Lanka. Evid Based Complement Altern Med. 2021;2021:1-12. doi:10.1155/2021/6644004

57. Kennedy MS, Masharani U. Pancreatic hormones \& antidiabetic drugs. In: Katzung BG, editor. Basic \& Clinical Pharmacology. 14th ed. McGrawHill; 2018:762-833.

58. Agem KF, Teke GN, Bathelemy N, Charles F, Jean-paul DLK. In vitro antifungal activity of Dorstenia mannii leaf extracts (Moraceae). Afri $J$ Biotechnol. 2015;14(46):3164-3169.

59. Sadasivan Nair AN, Raveendran Nair RV, Rajendran Nair AP, et al. Antidiabetes constituents, cycloartenol and 24-methylenecycloartanol, from ficus krishnae. PLoS One. 2020;15(6):1-21. doi:10.1371/journal.pone.0235221

60. Prabhakar PK, Doble M. Mechanism of action of natural products used in the treatment of diabetes mellitus. Chin J Integr Med. 2011;17(8):563574. doi:10.1007/s11655-011-0810-3

61. Chao J, Cheng HY, Chang ML, et al. Gallic acid ameliorated impaired lipid homeostasis in a mouse model of high-fat diet-and streptozotocininduced NAFLD and diabetes through improvement of $\beta$-oxidation and ketogenesis. Front Pharmacol. 2021;11:1-14. doi:10.3389/ fphar.2020.606759

62. Woldekidan S, Mulu A, Ergetie W, et al. Evaluation of antihyperglycemic effect of extract of moringa stenopetala (Baker f.) aqueous leaves on alloxan-induced diabetic rats. Diabetes Metab Syndr Obes Targets Ther. 2021;14:185-192. doi:10.2147/DMSO.S266794

63. Eleazu CO, Iroaganachi M, Okafor PN, Ijeh II, Eleazu KC. Ameliorative potentials of ginger (Z. officinale Roscoe) on relative organ weights in streptozotocin induced diabetic rats. Int J Biomed Sci. 2013;9(2):82-90.

64. Lavle N, Shukla P, Panchal A. Role of flavonoids and saponins in the treatment of diabetes mellitus. J Pharm Sci Biosci Res. 2016;6(4):535-541.

65. Dufall KG, Ngadjui BT, Simeon KF, Abegaz BM, Croft KD. Antioxidant activity of prenylated flavonoids from the West African medicinal plant Dorstenia mannii. J Ethnopharmacol. 2003;87(1):67-72. doi:10.1016/S0378-8741(03)00108-9

66. Peniche-Pavía HA, Vera-Ku M, Peraza-Sánchez SR. Phytochemical and pharmacological studies on species of dorstenia genus (2000-2016). J Mex Chem Soc. 2018;62(3):9-23. doi:10.29356/jmcs.v62i3.381

67. Basel Declaration Society. Research at a Crossroads. Basel Declaration A: a call for more trust, transparency and communication on animal research; Basel connference; Basel. 2010:1-2.

68. International Council for Laboratory Animal Science. ICLAS ethical guideline for researchers. 2015:5-6.

69. European Union. Legislation for the protection of animals used for scientific purposes. Commission E, editor. 2010:1-12.

Journal of Experimental Pharmacology

Dovepress

\section{Publish your work in this journal}

The Journal of Experimental Pharmacology is an international, peer-reviewed, open access journal publishing original research, reports, reviews and commentaries on all areas of laboratory and experimental pharmacology. The manuscript management system is completely online and includes a very quick and fair peer-review system. Visit http://www.dovepress.com/testimonials.php to read real quotes from published authors.

Submit your manuscript here: https://www.dovepress.com/journal-of-experimental-pharmacology-journa 